\title{
Teaching Certificate Redesign: Making a Flexible Program for Future Faculty
}

\author{
Kate Z. Williams, Lauren E. Margulieux, \\ and G. David Lawrence
}

\begin{abstract}
Higher education teaching certificate programs can improve graduate students' and postdoctoral scholars' teaching while preparing them for their future roles as faculty, providing a multi-tiered benefit to universities' teaching goals. This article documents the decision points and initial success of a redesign of one such teaching certificate program." As part of the redesign process, 10 universities' programs were reviewed and used as a benchmark. The programs' learning objectives and assessments, along with their connections to the literature, are discussed in detail. A new flexible pathway through the certificate program emerged, tapping into courses, workshops, and online resources for content delivery, effectively expanding access to more participants. Preliminary outcomes include increased enrollments from a wide range of disciplines and new opportunities for partnerships with academic departments.
\end{abstract}

Keywords: preparing future faculty, graduate student education, postdoctoral scholar development, teaching development programs, teaching certificate, center for teaching and learning, backward design

Teaching development programs that enhance graduate student teaching skills provide two important benefits: they improve the qual- 
ity of teaching that graduate student instructors and teaching assistants provide for undergraduates, and they provide important professional development for emerging faculty (Adams, 2002; Austin et al., 2009; Cascella \& Jez, 2018; Ebert-May et al., 2015). Teaching development programs help graduate students to obtain and be more prepared for faculty positions, especially when the program offers a teaching certificate (Austin et al., 2008; Bruff, 2007; Meizlish \& Kaplan, 2008; Linse et al., 2004). For reviews of the effect of teaching development programs on graduate students and faculty, see Boylan (2003), Connolly et al. (2016), and Linse et al. (2004).

In the early 1990s, the Council of Graduate Schools and the Association of American Colleges and Universities (AAC\&U) called for a greater focus on preparing graduate students to teach in higher education. With the goal of transforming the way new faculty are prepared for careers in academia, graduate programs began creating and institutionalizing programs to provide aspiring faculty members with opportunities to explore faculty roles, including enhancing their preparation to teach, learning about faculty governance, understanding institutions of higher education with different missions, and receiving feedback from teaching mentors (Bogle et al., 1997; DeNeef, 1996; Medina et al., 2015). Grant opportunities encouraged the development of preparing future faculty programs, which often emphasize teaching development, at doctoral institutions around the country (Council of Graduate Schools, n.d.).

In response to the national call for teaching development programs, Georgia Institute of Technology (Georgia Tech) developed the Tech to Teaching certificate for graduate students preparing for academic faculty positions. The first 7 years of the program were marked by uneven participation across different academic disciplines and low participation relative to graduate student enrollment. This problem is not unique to our institution. Teaching development programs tend to have low participation rates because graduate students and their advisors are evaluated for developing their research skills rather than other professional skills, like teaching (Sales et al., 2007). In addition, the 
four-semester, academic, credit-bearing structure of the program prohibited some graduate students and all postdoctoral scholars from participating. To increase the impact of the teaching certificate, a program review and redesign was conducted. This article describes the review and redesign process, which was based, in part, on new developments in the literature and a review of similar programs at peer institutions. To complement the description of the redesign, preliminary outcomes from the first several years of the new program are discussed.

After the redesign, the teaching certificate program has seen higher overall participation rates, especially from postdocs and in some academic disciplines that had been underrepresented previously. The redesign has also fostered partnerships with academic departments to adapt the program elements specifically for their students and offer unique pathways to earning the certificate that satisfy the demands of the certificate and the constraints of the departments. By consolidating national resources and ideas from programs at multiple institutions, the design of the new certificate program is applicable to similar teaching development efforts at other institutions.

\section{Program Review}

\section{Review of Existing Program}

Georgia Tech originally founded the Tech to Teaching certificate in 2009 with funding from a National Science Foundation grant. The goal of the program was to provide professional development opportunities to students who were interested in careers that included teaching. Despite the importance of job candidates' teaching experience at research- and teaching-focused institutions (Bruff, 2007; Fleet et al., 2006; Meizlish \& Kaplan, 2008), learning to teach is often neglected in academic PhD programs (Wulff \& Austin, 2004). Graduate students and postdocs often must look outside of their academic 
departments to centers of teaching and learning (CTLs) or other university-wide groups to find teaching development services (Connolly et al., 2016; Von Hoene, 2011). To fulfill this need, the program aimed to provide teaching development and a credential that students could leverage in their job searches to demonstrate a commitment to quality teaching.

The program offered a basic and advanced certificate. The basic certificate required

- a 3-credit-hour, theory-based course in which students learned about the fundamentals of teaching and learning; and

- a 3-credit-hour, practice-based course in which students taught a portion of a college-level course in their discipline with a faculty mentor.

In the practice-based course, students delivered guest lectures that were observed by the course instructor, a faculty mentor in their discipline, and their peers in the teaching certificate. Before and after teaching, they attended a peer learning community facilitated by the course instructor to discuss their lesson plans and experiences. The peer observations served two purposes: they provided feedback to the students who were teaching, and they gave students who were observing opportunities to learn from others' teaching.

To earn the advanced certificate, students completed

- the basic certificate;

- a 3-credit-hour, theory-based course on course design; and

- a 1-credit-hour, practice-based course in which students taught a college-level course in their discipline as the instructor of record.

Again, students observed one another and attended a facilitated learning community to discuss their lesson plans and teaching experiences.

In the 7 years since inception, the program had served only a small portion of Georgia Tech's graduate students. A total of 230 
students had completed the first course, 72 students had completed the basic level certificate, and 21 students had completed the advanced level certificate. As a point of comparison, Georgia Tech had about 7,000 graduate students at the time, with about 1,000 of them employed as teaching assistants each semester. These numbers do not include approximately 350 postdoctoral scholars, many of whom are interested in careers that include teaching. Postdocs were unable to participate in the program because they are not students and, therefore, were restricted from registering for courses for academic credit. The steep decline between the number of students who started the program and finished the program indicated barriers to completion.

To better understand the limitations and barriers of the current program, we asked graduate students who had started the program but not earned a certificate to tell us why they had left the program. The four most common responses were that (a) they did not have time to take additional courses; (b) their schedule did not permit meeting regularly for a semester-long course (e.g., due to data collection responsibilities in the lab); (c) they did not have an opportunity to be instructor of record to complete the advanced certificate; and (d) their advisor did not support them taking courses that were not required for their degree program.

At the same time that we were assessing the success of the existing program, we also received new resources to support the program. Georgia Tech joined the Center for the Integration of Research, Teaching, and Learning (CIRTL). CIRTL offers workshops and short courses on a variety of teaching development topics to prepare future faculty. In addition to CIRTL, Georgia Tech joined Linkedln Learning (formerly Lynda.com), a fee-based, online learning environment that offers lectures and activities on a wide range of topics, including pedagogical topics such as creating learning objectives. To gather ideas about how to integrate these new resources and to ensure that our redesigned program was of similar quality to other teacher development programs, we reviewed the teaching programs offered by peer institutions. 


\section{Review of Programs at Peer Institutions}

We reviewed teaching development programs that were offered by CTLs or graduate schools at 10 peer institutions to benchmark our existing program against others and identify best practices. The criteria for a peer institution included similar research productivity (i.e., very high research productivity), similar institutional priorities (i.e., primarily STEM-focused institution), similar number of students (i.e., midsized university), or similar location (i.e., southeastern United States). The institutions were Arizona State University, Emory University, Johns Hopkins University, Massachusetts Institute of Technology, University of Georgia, University of Minnesota, University of Notre Dame, University of Washington, University of Wisconsin-Madison, and Vanderbilt University.

We reviewed only campus-wide future faculty programs for graduate students (and postdocs, if included). We did not examine departmental- or college-level teaching development programs that were restricted to specific disciplines because our goal was to redesign a campus-wide program that served all future faculty regardless of academic field. We also excluded orientations or courses required for teaching assistantships or graduate student instructor positions. While some TAs go on to faculty positions, preparing graduate students for their current jobs as TAs and preparing future faculty for teaching positions in higher education necessarily differ. Therefore, to ensure our review did not conflate these programmatic goals, we eliminated TA training programs from our review.

Information about the institutions' future faculty development programs and services, including teaching certificates, was collected from their programs' websites. For each institution, the authors created a complete list of services, such as workshops, courses, and mentoring. In addition, we captured the topics that were covered by the services, such as creating lesson plans or inclusive teaching, to inform development of learning objectives for our program. Once we compiled this information for each institution, we compared the programs to iden- 
tify similarities and overall themes. Some commonalities among the future faculty programs included formal courses, workshops, and symposia on teaching and learning.

A review of the programs revealed eight out of 10 institutions offered a teaching certificate. With one exception, these non-creditbearing certificates were earned through seminar-based programs, usually requiring attendance at five to eight workshops to earn the certificate. Three of the centers offered an advanced certificate, requiring attendance at five to eight additional workshops.

Several key points emerged from this review that informed our assessment of our current program. We noticed that our existing course-based certificate was more rigid than other schools' workshopsbased programs, which built opportunities for participant choice into the menu of program options. Likewise, our program required two to four semesters of time-intensive commitment, whereas other schools' programs appeared more flexible to graduate students' schedules. While many of the topics offered at other institutions were embedded in our course and workshop offerings, we also noticed that other programs offered workshops on inclusive teaching and teaching with technology, topics that were not fully integrated into our existing certificate.

\section{Program Redesign}

We chose to follow backward design — planning with the end in mind -as the framework to structure the redesign efforts. Often applied to course or module development, backward design allowed us to focus our planning efforts on what participants should know and be able to do by the culmination of the certificate. Successful teaching development curricula have clear, measurable learning objectives that are supported by structured, scaffolded learning opportunities and are evaluated with meaningful assessments (Hines, 2015; Wiggins \& McTighe, 2005). Using the backward design framework, we began to rebuild the program 
starting with identifying the learning objectives and working backward to structure the program to reach those objectives.

\section{Designing Learning Objectives}

Although learning objectives were part of individual courses in the previous certificate program, no programmatic goals guided the full certificate. In the creation of program-level learning goals (see Table 1), the existing course outcomes were considered, along with a review of the literature in graduate student professional development and a review of similar programs at other institutions, as discussed previously.

Table 1. Foundation-Level Learning Objectives in Tech to Teaching Program Paired With Learning Objectives From the Literature

LEARNING OUTCOMES FOR FOUNDATION LEVEL Von Hoene (2011) Phillips et al. (2011) Kalish et al. (2012)

F1. Explain how people learn

1a. Describe teaching methods that promote knowledge retention, transfer, and mastery

1b. Analyze discipline-specific SoTL literature

F2. Identify and explain strategies for learner motivation and inclusion

2a. Describe strategies for motivating students with different goals ${ }^{a}$

2b. Describe strategies for creating an inclusive classroom

$x-x$

F3. Identify and explain evidence-based teaching

$\begin{aligned} & \text { 3a. Describe and develop evidence-based teach- } \\ & \text { ing methods and learning activities }\end{aligned}$
$\begin{aligned} & \text { 3b. Describe and develop methods for formative } \\ & \text { assessment of student learning }\end{aligned}$
X

F4. Develop a plan for assessing teaching and learning

\begin{tabular}{|c|c|c|}
\hline $\begin{array}{l}\text { 4a. Write specific and measurable learning objec- } \\
\text { tives }\end{array}$ & & $x$ \\
\hline $\begin{array}{l}\text { 4b. Describe and develop methods for measuring } \\
\text { learning objectives }\end{array}$ & $x$ & $x$ \\
\hline
\end{tabular}

F5. Integrate educational technology with effective teaching

5a. Explain effective uses of technology in teach-

$X$ ing and learning

5b. Explain universal principles of design for learning (UDL) 


\section{LEARNING OUTCOMES FOR TEACHING} CAPSTONE LEVEL

\section{T1. Apply foundational knowledge to teaching experiences}

1a. Write a lesson plan that specifies learning $\mathrm{X}$ $x$ objectives, activities, assessment methods, and strategies for including and motivating students

1b. Demonstrate application of foundational knowledge during teaching ${ }^{b}$

T2. Demonstrate professional and effective communication

2a. Demonstrate appropriate and intentional use of delivery methods for your instructional content

2b. Demonstrate welcoming and respectful interpersonal communication

$\mathrm{x}$

$\mathrm{X}$

X $x$

T3. Engage in critical analysis of your and others' teaching

3a. Assess your and others' teaching and identify strengths and areas for growth

3b. Collect and reflect on feedback from students, peers, and mentors on your teaching skills

aMotivation was identified by Ambrose et al. (2014) and UDL was identified by Meyer et al. (2014).

${ }^{b}$ Application of foundation-level knowledge is conceived as higher-order Bloom's (1956) level.

A review of the literature provided several examples of best practices in graduate teaching program outcomes. Von Hoene (2011) reported the following outcomes commonly associated with the awarding of a teaching certificate: conduct effective discussions, prepare and give lectures, teach ethically, create inclusive classrooms, assess learning, write a syllabus, understand how people learn, articulate a teaching philosophy, and conduct classroom/action research. Phillips et al. (2011) identified the following outcomes from their review of the existing literature: develop student learning outcomes, assess student learning, use technology to improve learning, and use feedback on teaching from peers/mentor. Kalish et al.'s (2012) list of pedagogical competencies suggested future faculty should use teaching techniques aligned with principles of how people learn, set learn- 
ing goals, use inclusive teaching practices, assess student learning, use evidence-based and discipline-specific teaching practices, and selfassess to improve their own teaching practices. Finally, AAC\&U called for the ongoing development of preparing future faculty programs that address the full range of needs of aspiring faculty, including to communicate outside of their disciplines, use educational technology, and practice inclusive teaching that meets the needs of diverse learners (Goldsmith et al., 2004). Some resources offer more specific guidance for particular disciplines, such as Pruitt-Logan et al.'s (2002) Preparing Future Faculty in the Sciences and Mathematics or Gaff et al.'s (2003) Preparing Future Faculty in the Humanities and Social Sciences. Only discipline-independent recommendations from these publications were considered because Georgia Tech's teaching certificate program serves students in all disciplines.

Based on the review of teaching development program content in the literature and peer programs, three faculty associated with the teacher certificate program brainstormed an initial set of possible learning outcomes. Next, the full faculty at the CTL participated in a sorting exercise to group similar and overlapping topics, eliminate criteria that were not essential, and offer additional learning objectives for consideration. During this process, Ambrose et al. (2010) helped us identify student motivation for learning as an additional learning outcome that had not emerged from the previous literature review. Likewise, our commitment to fully integrating both inclusive teaching and educational technology into the revised program design led to the creation of a learning outcome centered on universal design for learning (Meyer et al., 2014).

Through this deliberation, a distinction was noted between what students should know and what students should be able to do by completion of the certificate. As we worked to differentiate between these two types of learning objectives, two levels of the program emerged. The foundational level included learning objectives centered on the type of knowledge participants would gain and aligned with Bloom's (1956) lower-order levels of remembering and understanding. The 
teaching capstone level included learning objectives that allowed participants to practice or demonstrate skills, reflecting higher-order skills of applying, analyzing, evaluating, and creating (Bloom, 1956). At each level, similar objectives were condensed and others expanded until we produced a thorough yet manageable framework to capture the essential knowledge and skills necessary to award a teaching certificate. The foundation level emerged with five primary learning objectives, each with two sub-objectives, and the capstone level contains three primary objectives, again each with two sub-objectives. In Table 1 , the program outcomes are matched with those identified in the related literature.

\section{Designing Assessments}

With a framework for the program-level learning objectives, our next step in the backward design process was to determine how achievement of the learning objectives would be measured. Our review of other programs revealed a common attendance-based workshop model, in which participants earned the certificate after attending a certain number of workshops. While we wanted to start offering workshops as an alternative route to earn the certificate, there are several weaknesses of using participation as a sole criterion for evaluation (Hines, 2011, 2015). First, attendance at a workshop does not necessarily provide evidence that learning had occurred (Hines, 2011). In our case, we were particularly cautious because some learning resources would come from sources outside the institution. Second, a menu approach to workshop attendance (i.e., participants pick five workshops to attend) meant participants would miss some of the learning objectives. Finally, attending workshops on isolated topics, potentially over several years, does not necessarily provide a synthesized knowledge of teaching (Hines, 2011), a feature we hoped to maintain from the original program design.

Our courses on teaching already included assignments that would demonstrate student learning. To assess learning in the non-course con- 
text, we created an assignment for each sub-objective to serve as evidence that learning had occurred. These assignments required students to demonstrate the concepts that they had learned and could later be used in a teaching portfolio. This approach has been successful for other CTLs (Hines, 2011) and conforms to Hines's (2015) recommendations for evaluating faculty development programs. For each of the 10 foundationlevel sub-objectives, participants are required to write a paper, respond to a scenario, or create parts of a syllabus or lesson plan for a course in their content area. For example assignments, see Table 2.

Each of these 10 assignments should take a well-prepared participant between 1 and 2 hours to complete after attending the associated learning experience. Participants are usually allowed 1 month after the associated learning experience to submit the evidence of learning through the campus learning management system. The faculty member who presented the workshop reviews the submissions to evaluate understanding and application of key principles. In addition, the faculty member provides feedback to the participant. If the submission satisfies the learning requirement, the certificate program administrator logs the participant's completion; if the submission does not sufficiently demon-

\section{Table 2. Sample of Learning Objectives Paired With Assessments}

\begin{tabular}{|c|c|}
\hline Learning objective & Assessment \\
\hline $\begin{array}{l}\text { 2a. Describe strategies for motivating } \\
\text { students with different goals }\end{array}$ & $\begin{array}{l}\text { Respond to a case from Ambrose et al. (2010) } \\
\text { and make recommendations for motivating stu- } \\
\text { dents to read primary documents to prepare } \\
\text { for class discussions }\end{array}$ \\
\hline $\begin{array}{l}\text { 3a. Describe and develop evidence- } \\
\text { based teaching methods and learning } \\
\text { activities }\end{array}$ & $\begin{array}{l}\text { Propose evidence-based teaching techniques } \\
\text { that can be used to improve a fictional course } \\
\text { in your discipline }\end{array}$ \\
\hline $\begin{array}{l}\text { 3b. Describe and develop methods for } \\
\text { formative assessment of student } \\
\text { learning }\end{array}$ & $\begin{array}{l}\text { Select a classroom assessment technique that can } \\
\text { be used to measure a specific lesson's learning } \\
\text { goals and write a brief paper to explain how to } \\
\text { administer the assessment and how you would } \\
\text { use the information you gather }\end{array}$ \\
\hline $\begin{array}{l}\text { 5a. Explain effective uses of technology } \\
\text { in teaching and learning }\end{array}$ & $\begin{array}{l}\text { Write a technology plan for a specific course that } \\
\text { outlines what technologies you would use, how } \\
\text { it is expected to enhance student learning, and } \\
\text { how you will manage contingencies such as } \\
\text { training, cost, and technical difficulties }\end{array}$ \\
\hline
\end{tabular}

To Improve the Academy • Vol. 39, No. 2 • Fall 2020 
strate proficiency, the participant is asked to revise and resubmit. These assignment requirements are waived if a course is used to satisfy the learning objective because passing the course serves as evidence of learning. For a complete list of assignments, please contact the authors.

The learning objectives at the capstone level took on a different format. Instead of requiring an assignment to match each learning objective at the capstone level, the learning objectives serve as guidance for the development of the capstone experience and are included in the syllabus for the capstone seminar. To demonstrate achievement of the capstone level learning objectives, participants develop a final portfolio that includes a summary of their teaching feedback and their teaching philosophy statement.

\section{Multiple Pathways to Completion}

After developing the learning outcomes and assessment tools, we then considered how to deliver the content in a flexible manner to a diverse audience of graduate students and postdoctoral scholars. To achieve this goal, we developed multiple pathways to prepare participants for the assessments and thus achieve the learning objectives. We considered the existing courses, CIRTL's seminars and workshops, online resources like Linkedln Learning, and our own courses.

\section{Foundation-Level Objectives}

Starting with our two existing content courses, the course-level learning objectives were revised to align with the new program-level objectives. The first three objectives were assigned to the first course, and the last three objectives were assigned to the second course. The third objective became a part of both courses because both courses have historically integrated evidence-based teaching methods. Course instructors can use the program's learning outcome assessments or create their own equivalent assessments.

Leveraging the resources of online sources, we identified learning 
opportunities that align with the program's learning objectives. The CIRTL resources range from 90-minute workshops to 6-week asynchronous massive open online courses (MOOCs) to 8-week synchronous courses. Each semester, we map the learning outcomes embedded in the CIRTL offerings to our foundation-level learning outcomes. In addition, vetted on-demand coursework available through Linkedln Learning was identified to satisfy learning objectives about creating learning objectives, teaching with technology, and universal design for learning. Participants use these online resources to satisfy the learning goals and then submit a response to the associated assignment via the program's learning management site.

The CTL resurrected a teaching workshop series aimed at graduate students and postdoctoral scholars. Although faculty development workshops traditionally enjoy robust participation on our campus, the attendance at future faculty workshops had fallen off to the point that the workshop series had been tabled by CTL administration. This revived workshop series is now instrumental to delivering the core content of the certificate. A slate of eight 90-minute workshops was developed to align with the foundation-level learning objectives. Like those who complete online learning opportunities, students who attend the workshops demonstrate their learning by submitting a response to the associated assignment.

By mapping the learning objectives to a variety of learning experiences at the foundational level, we created an opportunity for choice (for an example, see Table 3). Participants can satisfy the learning outcomes by using any combination of resources to create their own independent pathway. For example, participants can pursue a course, a portion of the on-campus workshop series, and an online resource to create their own pathway through the foundation level of the certificate. We recognize that different pathways may include different levels of effort and time; however, by structuring the program toward the achievement of learning objectives, we minimize the concern over this inequity. The courses meet the learning objective requirements while expanding students' experience in a variety of ways. 
Table 3. Example Pathway Options

\begin{tabular}{|c|c|}
\hline \multicolumn{2}{|c|}{ Example Pathway 1-Coursework } \\
\hline Objectives 1-3 & Pass first CTL credit-bearing course in the certificate series \\
\hline Objectives 3-5 & Pass second CTL credit-bearing course in the certificate series \\
\hline Teaching capstone & Participate satisfactorily in CTL credit-bearing capstone seminar \\
\hline \multicolumn{2}{|c|}{ Example Pathway 2-Coursework plus workshops } \\
\hline Objectives 1-3 & Pass first CTL credit-bearing course in the certificate series \\
\hline Objectives $4 a$ \& 4b & $\begin{array}{l}\text { Complete vetted Linkedln Learning course on assessment; sub- } \\
\text { mit assessments for } 4 a \text { and } 4 b\end{array}$ \\
\hline Objective $5 a$ & $\begin{array}{l}\text { Attend in-person CTL workshop on teaching with technology; } \\
\text { submit assessment for } 5 a\end{array}$ \\
\hline Objective $5 b$ & $\begin{array}{l}\text { Attend online CIRTL workshop on universal design for learning; } \\
\text { submit assessment for } 5 b\end{array}$ \\
\hline Teaching capstone & $\begin{array}{l}\text { Participate satisfactorily in non-credit-bearing CTL capstone } \\
\text { seminar }\end{array}$ \\
\hline \multicolumn{2}{|c|}{ Example Pathway 3-Workshops } \\
\hline $\begin{array}{l}\text { Objectives 1a, 2a, 2b, 3a, } \\
\quad 4 a, 4 b\end{array}$ & Complete 8-week online CIRTL MOOC \\
\hline Objective $1 \mathrm{~b}$ & $\begin{array}{l}\text { Complete scholarship of teaching and learning article analysis } \\
\text { (independent study); submit assessment for } 1 \mathrm{~b}\end{array}$ \\
\hline Objective $3 b$ & Attend in-person CTL workshop; submit assessment for $3 b$ \\
\hline Objectives $5 a$ \& $5 b$ & $\begin{array}{l}\text { Complete vetted Linkedln Learning course on teaching with } \\
\text { technology; submit assessments for } 5 \mathrm{a} \text { and } 5 \mathrm{~b}\end{array}$ \\
\hline Teaching capstone & $\begin{array}{l}\text { Participate satisfactorily in non-credit-bearing capstone seminar } \\
\text { offered by the CTL }\end{array}$ \\
\hline
\end{tabular}

\section{Capstone-Level Objectives}

At the capstone level, one of the biggest changes that we made is the amount of required teaching experience. A barrier in the previous program was the limited amount of teaching experience available to graduate students and postdocs, especially as instructors of record. Although teaching independently as instructor of record is valuable preparation for faculty positions, very few graduate students at this institution have the opportunity to do so. Therefore, we consider serving as instructor or co-instructor to be equivalent for the sake of the teaching certificate. Co-instructors work under a teaching mentor and deliver approximately 2 weeks of course material. Certainly, future faculty teaching their own course gain a deeper professional develop- 
ment experience compared to those who co-teach. However, the purpose of the capstone is not to certify "master teachers" but to provide formative assessment and support as these emerging instructors practice their craft, sometimes for the very first time.

Every capstone participant is required to deliver two substantial (e.g., hour-long or more) teaching demonstrations. A CTL representative attends and video records these teaching demos, collects and summarizes feedback from the enrolled students, and provides the capstone participant with a comprehensive review of the teaching demonstration. Because these observations are intended to be developmental rather than evaluative, we elected not to apply a standard rubric to these observations. Rather, the observer frames their feedback around the learning goals set forth in the participant's lesson plan, the instructional strategies chosen to achieve those goals, any formative assessment employed to measure the learning goals, the participant's presentation skills, and the apparent classroom climate established by the participant.

A cohort-based learning community is a critical component to the capstone experience. The capstone can be completed as a CTL course or through a school's teaching practicum course. Members of the cohort review one another's lesson plans and watch one another's teaching to provide feedback. This system provides participants ample feedback on their teaching and gives participants opportunities to learn from their peers. In fact, because the CTL capstone cohorts integrate future faculty from broad disciplines across campus, members experience a rare opportunity to observe teaching in disciplines outside of their own. This system protects an important aspect of teaching development, peer feedback, while still reducing the barriers involved in the previous program.

\section{Preliminary Program Evaluation}

With a more flexible program, we have already seen the number of participants grow. The program is advertised through graduate stu- 
dent orientation, on the CTL website, via graduate student and postdoc newsletters, and through word of mouth. In seven semesters since the new program was unveiled, we have welcomed 383 new members, tripling the previous program's growth of about 30 students per year. In 3.5 years, 105 graduate students and 11 postdoctoral scholars have completed the newly revised certificate requirements, compared to the 93 participants who earned either certificate over the 6 years of the previous program design.

The new participants are embracing the new pathways toward certificate completion. The revived workshop series has high participation. In the first full year of the revised program, a total of 91 participants attended at least one workshop in the series; in Year 2, attendance climbed to 170 participants. Postdoctoral scholars made up about $27 \%$ of the participants, a previously unserved population. For the capstone experience, about three-quarters of those who completed the new program co-taught a course rather than served as instructor of record. Postdocs and students without opportunities to be instructor of record previously could not participate in this part of the teaching development program.

Though participants are using the new pathways, many are still engaging in the original courses. Students seem to understand that the courses offer a deeper level of involvement that takes more time but also offers additional development. In fact, of the 116 participants who have completed the program in the four semesters since the redesign, $78 \%$ enrolled in at least one of the two academic courses, and $51 \%$ satisfied the foundation-level learning outcomes by enrolling in both courses. The difference from the original system to the new system is that participants are taking advantage of multiple pathways. The remaining $49 \%$ of participants satisfied other requirements with pre-approved online courses through the institution's access to Linkedln Learning (45\%), the on-campus workshop series offered by the CTL (27\%), and CIRTL online workshops or courses (9\%).

Upon entry to the program and again at completion of the capstone, participants complete a knowledge survey about their familiar- 
ity with the primary learning outcomes. Nearly 100 people have completed both the entrance and exit surveys since the program redesign. The survey uses a 4-point Likert scale (anchors are $4=1$ know what this is and could explain it to others, $3=1$ know what this is but can't explain it to others, 2 = I have heard of this but don't know what it means, and $1=$ I've never heard of this) to report their familiarity with each learning outcome at the foundation level. The average score across items and across participants upon entry is 2.74 . On exiting the program, this average knowledge rating increased to 3.87 , with the largest gains in (a) how universal principles of design support learning for all students $(M=1.57)$, (b) how to write specific and measurable learning outcomes $(M=1.43)$, and (c) evidence-based teaching methods and learning activities $(M=1.39)$. In addition to this quantitative data, the exit survey captures student reaction to the certificate program. Participants were asked to describe the elements of the teaching certificate program they like best; the following quotations were selected as representative of the types of comments received.

I appreciate that Tech to Teaching practices what it preaches. To be able to learn about various classroom techniques in an environment that actively utilizes them is a great way to broaden our exposure to the concepts in practice.

While the capstone teaching requirement was very impactful, I think the thing that I liked most about the Tech to Teaching program was taking [the classes]. The ability to spend time learning and discussing various teaching methodologies and techniques really broadened my scope.

I love how efficient it is. Tech to Teaching is not a long program, but I feel that I have learned a huge amount in a very short time and that all of the learning objectives are appropriate and useful. I also enjoyed how flexible Tech to Teaching was. As a graduate student, it's hard to find the extra time to devote to non-research pursuits, but Tech to Teaching made it easy to pursue becoming a better teacher while still staying on top of my work.

To be honest, I mostly appreciate that there is such a program and a group of energetic people behind it at all. I did my under- 
graduate degree at a university with a research orientation like Georgia Tech. But there was no such teaching program there, and relatively few of the professors put much energy into their lectures. I appreciate that an institution like Georgia Tech cares also about "educating about education."

\section{Discussion}

Based on preliminary data from the first 2 years of the new program, the changes have had their intended effect on the program-increased enrollment in the program, increased diversity of participant academic majors, and increased flexibility of pathways toward certificate completion. Although the increased volume has required an investment of additional resources, it has not demanded a proportional increase in work from the CTL faculty due to using online resources from CIRTL and Linkedln Learning. Our workshop attendance has increased, as has enrollment for courses, leading to a robust pipeline of participants in the face-to-face professional development programming. This success means additional staff time was needed for marketing the program and orienting new members, teaching workshops and courses, evaluating assignments, supervising capstone experiences, and communicating with constituents across the institution. To meet this growing need, we launched a new peer mentor program called Graduate Teaching Fellows. In the first year of the program, we secured funding to hire two 20-hour-per-week graduate teaching assistants who assist with intake of new certificate members and coordinate classroom observations for participants of the teaching capstone. Along with six additional Fellows who will contribute 60 hours per semester to TA development and future faculty programming, the Fellows participated in extensive training to prepare them to observe and provide feedback to the Tech to Teaching participants completing the teaching capstone. The Fellowship is an advanced professional development opportunity for these future faculty, all of whom have extensive 
teaching experience and most of whom have completed the Tech to Teaching certificate program.

The redesign also opened doors for new opportunities to expand the program in light of a growing campus commitment to teaching development outside of the CTL. Consequently, over the past year, we have established new partnerships with five academic units to link the Tech to Teaching program with their departmental professional development efforts. Each year, these departments recruit and select two to six new participants into their teaching development program and require them to complete the Tech to Teaching certificate as one element of their apprenticeship, along with additional exposure to faculty roles and responsibilities within the discipline. The schools of History, Economics, and Industrial Engineering are using our new partnership to prepare graduate students to serve as independent course instructors by their 3rd or 4th year. Biomedical Engineering and Civil Engineering target 3rd- and 4th-year students headed to academic faculty positions to participate in the program. Departments have leveraged a small campus grant program or internal funding to provide participants a financial incentive of $\$ 2,000$ to $\$ 4,000$ to support travel or other professional development in teaching. These partnerships have provided a model by which to expand the certificate's reach and reputation for preparing faculty for the academy.

\section{Limitations and Future Directions}

As with any program design, limitations exist. Despite the opportunities now available through the flexible pathways, some academic programs continue to be overrepresented in enrollment (i.e., engineering) while others are underrepresented (i.e., business) based on total graduate enrollment. Some of this variance is influenced by the differential teaching development available to graduate students and postdocs through their degree programs. Likewise, although the certificate program is now open to postdoctoral scholars, they make up only about $20 \%$ of current program members. More research is needed to under- 
stand if this is a limit of the program design or of the postdoctoral scholars' position, such as their available time or support received from their principal investigator.

Looking forward, there are several opportunities for continued research. First, we would like to compare performance outcomes achieved through different pathways to determine if the learning opportunities are indeed equivalent. Because participants from all pathway options intermingle in the teaching capstone experience, this investigation could be conducted through the teaching observation process embedded in the capstone. National studies are underway through CIRTL to estimate the effect of teaching development programs on future job prospects. A better understanding of the effects of the certificate on participants' academic job search outcomes would help us not only advertise the program but also fine-tune the learning experiences to best prepare participants for faculty positions.

\section{Conclusion}

Through our redesign, two major program design choices contributed to the development of a successful program.

1. Backward design was leveraged to create a comprehensive professional development program in college teaching. Clarifying what students will know and be able to do by the end of the teaching certificate created a central theme that now guides program offerings. Embedding assessments of learning into program pathways ensures participants achieve the anticipated learning goals while they build a portfolio of evidence that justifies certificate achievement.

2. Diverse learning activity pathways and assessments create flexibility while maintaining rigor. Delivering multiple pathways through various media (i.e., face-to-face class, face-to-face workshop, online class, and online asynchronous workshop) makes teaching develop- 
ment attainable to future faculty who could not participate in a more rigid, time-intensive program.

Due to our efforts to redesign the certificate using the backward design framework, we can confidently attest to the knowledge and skills participants gain through the certificate, as evidenced by their teaching portfolio at the foundation level and teaching observation feedback at the capstone level. By building the program around learning objectives, we have increased program enrollment, expanded participation in workshops and courses, and opened access for a larger group of graduate students and postdoctoral scholars preparing for faculty positions.

\section{Biographies}

Kate Z. Williams is a Senior Academic Professional and Assistant Director in the Center for Teaching and Learning at Georgia Institute of Technology. She develops and manages programs to support professional development in teaching for faculty, graduate students, and postdoctoral scholars. Her research interests include the design and assessment of initiatives that promote inclusive teaching and mentoring.

Lauren E. Margulieux is an Assistant Professor of Learning Sciences at Georgia State University. Her research interests are in educational technology and online learning, particularly for computing education. She focuses on designing instructions in a way that supports online students who do not necessarily have immediate access to a teacher or instructor to ask questions or overcome problem-solving impasses.

G. David Lawrence is the Associate Director of the Center for Teaching and Learning at the Georgia Institute of Technology. His research interests center on learning environments and instructional strategies that promote student well-being. One of his primary responsibilities is 
the creation and delivery of programming and services that enhance graduate student teaching and preparing future faculty.

\section{References}

Adams, K. A. (2002). What colleges and universities want in new faculty. Preparing future faculty occasional paper series (Number 7). Association of American Colleges and Universities.

Ambrose, S. A., Bridges, M. W., DiPietro, M., Lovett, M. C., \& Norman, M. K. (2010). How learning works: Seven research-based principles for smart teaching. Jossey-Bass.

Austin, A. E., Campa, H., III, Pfund, C., Gillian-Daniel, D. L., Mathieu, R., \& Stoddart, J. (2009). Preparing STEM doctoral students for future faculty careers. New Directions for Teaching \& Learning, 2009(117), 83-95. https://doi.org/10.1002/tl.346

Austin, A. E., Connolly, M. R., \& Colbeck, C. L. (2008). Strategies for preparing integrated faculty: The center for the integration of research, teaching, and learning. New Directions for Teaching and Learning, 2008(113), 6981. https://doi.org/10.1002/tl.309

Bloom, B. S. (1956). Taxonomy of educational objectives, handbook I: The cognitive domain. David McKay Co.

Bogle, E., Blondin, J. A., \& Miller, J. L. (1997). A memo to graduate students: Preparing to be the faculty of the future. Preparing future faculty occasional paper series (Number 5). Association of American Colleges and Universities.

Boylan, M. (2003). Evaluation of the Preparing Future Faculty Program (PFF). In Lessons from national programs, CIRTL Forum 2003, preparing the future STEM faculty: Sharing successful strategies. Center for the Integration of Research, Teaching, and Learning.

Bruff, D. (2007). Valuing and evaluating teaching in the mathematics faculty hiring process. Notices of the American Mathematical Society, 54(10), 1308-1315.

Cascella, B., \& Jez, J. M. (2018). Beyond the teaching assistantship: CURE leadership as a training platform for future faculty. Journal of Chemical Education, 95(1), 3-6. https://doi.org/10.1021/acs.jchemed.7b00705

Connolly, M. R., Savoy, J. N., Lee, Y. G., \& Hill, L. B. (2016). How teaching development programs can improve undergraduate education. Wisconsin Center for Education Research, University of Wisconsin-Madison.

Council of Graduate Schools. n.d. Prior preparing future faculty projects. Retrieved May 30, 2017, from http://cgsnet.org/ prior-preparing-future-faculty-projects 
DeNeef, A. L. (1996). Lessons of PFF concerning the job market. Preparing future faculty occasional paper series (Number 2). Association of American Colleges and Universities.

Ebert-May, D., Derting, T. L., Henkel, T. P., Maher, J. M., Momsen, J. L., Arnold, B., \& Passmore, H. A. (2015). Breaking the cycle: Future faculty begin teaching with learner-centered strategies after professional development. CBE-Life Sciences Education, 14(2), 1-12. https://doi.org/10.1187/ cbe.14-12-0222

Fleet, C. M., Rosser, M. F., Zufall, R. A., Pratt, M. C., Feldman, T. S., \& Lemons, P. P. (2006). Hiring criteria in biology departments of academic institutions. BioScience, 56(5), 430-436.

Gaff, J. G., Pruitt-Logan, A. S., Sims, L. B., \& Denecke, D. D. (2003). Preparing future faculty in the humanities and social sciences. Council of Graduate Schools and Association of American Colleges and Universities.

Goldsmith, S., Haviland, D., Daily, K, \& Wiley, A. (2004). Preparing future faculty initiative: Final evaluation report. Association of American Colleges and Universities. http://citeseerx.ist.psu.edu/viewdoc/download;jsessioni $\mathrm{d}=\mathrm{E} 12 \mathrm{EC} 6 \mathrm{AC28C6D02135D8DC2A52ADCE9B}$ ?doi=10.1.1.170.1961\&re $\mathrm{p}=$ rep $1 \&$ type $=$ pdf

Hines, S. R. (2011). How mature teaching and learning centers evaluate their services. To Improve the Academy, 30(1), 277-289. https://doi. org/10.1002/j.2334-4822.2011.tb00663.x

Hines, S. R. (2015). Setting the groundwork for quality faculty development evaluation: A five-step approach. The Journal of Faculty Development, 29(1), 5-12.

Kalish, A., Robinson, S.S., Border, L., Chandler, E., Connolly, M., Eaton, L.J., Gilmore, J., Griffith, L., Hansen, S., Pinder-Grover, T., and von Hoene, L. (2012). Steps toward a framework for an intended curriculum for graduate and professional students: How we talk about what we do. In A. Kalish, \& S. S. Robinson (Eds.), Mapping the range of graduate student professional development. In L.L.B. Border (Series Ed.) Studies in Graduate and Professional Student Development, 14. (pp. 163-173). Stillwater, OK: New Forums Press.

Linse, A., Turns, J., Yellin, J. M. H., \& VanDeGrift, T. (2004). Preparing future engineering faculty: Initial outcomes of an innovative teaching portfolio program. In Proceedings of the 2004 American Society for Engineering Education Annual Conference and Exposition (Vol. 3555).

Medina, M. S., Tomsek, J. J., \& Bowers-Pippin, J. (2015). The use of mentors and partnerships in a preparing future faculty program at a Health Sciences Center. Currents in Pharmacy Teaching and Learning, 7(2), 145-150. https://doi.org/10.1016/j.cptl.2014.11.008

Meizlish, D., \& Kaplan, M. (2008). Valuing and evaluating teaching in academic 
hiring: A multidisciplinary, cross-institutional study. The Journal of Higher Education, 79(5), 489-512. https://doi.org/10.1080/00221546.2008.1177 2114

Meyer, A., Rose, D. H., \& Gordon, D. (2014). Universal design for learning: Theory and practice. CAST Professional Publishing.

Phillips, A. C., Hansen, S., \& Willingham-McLain, L. (2011). Leveraging existing PFF (preparing future faculty) resources to create a certificate of university teaching. Studies in Graduate and Professional Student Development, 14, 126-145.

Pruitt-Logan, A. S., Gaff, J. G., \& Jentoft, J. E. (2002). Preparing future faculty in the sciences and mathematics. Council of Graduate Schools and Association of American Colleges and Universities.

Sales, J., Comeau, D., Liddle, K., \& Perrone, L. (2007). Preparing future faculty. Journal of College Science Teaching, 36(4), 24-30.

Von Hoene, L. (2011). Graduate student teaching certificates: Survey of current programs. Mapping the Range of Graduate Student Professional Development, 14, 101-113.

Wiggins, G., \& McTighe, J. (2005). Understanding by design (2nd ed.). Association for Supervision and Curriculum Development.

Wulff, D. H., \& Austin, A. E. (2004). Paths to the professoriate: Strategies for enriching the preparation of future faculty. Jossey-Bass. 